\title{
NEGOTIATING THE ‘CATCH-22': TRANSITIONING TO KNOWLEDGE WORK FOR UNIVERSITY GRADUATES WITH LEARNING DISABILITIES
}

\author{
Athena Goodfellow \\ Ph.D. Candidate, \\ Department of Geography, \\ McMaster University, \\ Hamilton, Ontario, Canada
}

\begin{abstract}
This paper examines the experiences of graduates with learning disabilities (GLD) transitioning into knowledge-based work in Ontario, Canada. The purpose of this paper is to identify and discuss the messiness in the universityto-work transition for GLD. To do so, this paper draws from interviews conducted with GLD in university and in the labour market. This paper first discusses the rise of the smart worker standard, a standard sensitive to socioculture norms, in recruitment of knowledge workers. The analysis of this paper examines three key stages of transition, namely: interviewing, employment testing and probationary period. This study's analysis demonstrates a 'catch-22' for GLD where they fear stigmatization through either disclosing their disability and non-disclosure where they risk being perceived as 'lazy' or 'incompetent'. The conclusion provides recommendations to support the transition experiences of GLD.
\end{abstract}

\section{INTRODUCTION}

7 The traditional tale of learning disability ${ }^{1}(\mathrm{LD})$ research often focuses on students in elementary and secondary school settings (see Brooks et al. 2008). Not captured by this literature are the students with LD who attend university and other postsecondary institutions. This absence in the LD literature is largely due to the fact that accessibility to postsecondary opportunities for persons with disabilities is relatively recent. Historically, students with disabilities were segregated in training and remedial education streams. This meant that the prospect of a university education was bleak, at best. Between the late 1980s and the early 1990s, the philosophical tide in 
elementary/secondary settings shifted from segregation to ideals of inclusion (see Artiles and Kozleski 2007). By the late 1990s, the educational prospects of pupils with disabilities had improved significantly. According to the Organization for Economic and Cooperative Development (OECD) (2003), between 1993 and 1999 Ontario postsecondary institutions witnessed a 125 percent increase in the population of students with disabilities. Almost a decade later, students with disabilities represent a substantive proportion (15.2 percent) of the student body in postsecondary settings (HRSDC 2009). On campus, students with LD comprise one of the largest (37.5 percent) disability sub-groups, account for between one-third to half of all academic accommodations (Harrison and Wolforth 2007; Holmes and Silverstein 2011). This wave of change has sparked doctoral research (see Meredith 2005; Yates 2009) and academic publications seeking to explore the experiences of transition for postsecondary graduates with learning disabilities (GLD) to work (see Greenbaum, Graham and Scales 1996; Madaus 2008; Madaus, Zhao and Ruban 2008).

This study seeks to advance an understanding of the experience of university GLD as they negotiate their transition into paid employment. Specifically, this study contributes to an understanding of how students with LD face a 'catch-22' 2 situation disability disclosure. That is to say, they face a dilemma to either disclose their impairment for the purpose of receiving accommodations, which bears the risk of being subject to stigmatization; or they choose to not reveal their disability in order to avoid potential stigma, which could preclude their access to workplace accommodations. The experiences of GLD represent an important, yet underexplored, topic of inquiry. As a whole, university graduates with and without disabilities comprise the largest underemployed cohort with one in five reporting employment in a position that required at most high school education (Li, Gervais and Duval 2006). The employment and earnings gaps between nondisabled graduates and their GLD peers with a bachelor's degree are narrowing 3 . However, the experiences of entering employment differ. Holmes and Silverstein (2011) report that the majority of GLD (72 percent) feel their performance at work is negatively impacted by their impairment, yet they chose not to disclose their impairment (62 percent), often for fear of stigmatization. In spite of a growing number of university graduates with LD transitioning into the workforce, there is actually little known about how GLD negotiate their transition into knowledgebased work.

This article is divided into five sections. The first section considers the available literature on the employment of persons with disabilities and explores the theoretical premise of the smart worker standard. The second section discusses the methodological considerations of this study. The results section, the third section, analyzes three key transition phases: interviewing, employment testing and probation period. The discussion, the final section, proposes how these experiences offer insight to educators, service providers, employers and 
policy-makers in the field of higher education regarding support strategies for transition of GLD. In the conclusion, the final section, consideration is given to the value of this study pertaining to the existing knowledge of disability and the transition into the knowledge work, that is to say work which derives primarily from cognitive tasks such as engineering or accounting.

\section{LITERATURE REVIEW}

\section{EMPLOYMENT OF PERSONS WITH DISABILITIES AND LEARNING DISABILITIES}

This section explores the current literature on the negotiation of workplace spaces and workplace standards for persons with disabilities. Particular consideration is given to the concept of the smart worker standard and the politics of 'passing' ${ }^{4}$ as it relates to GLD's transition into work. As a whole, persons with disabilities continue to face unfavorable labour market outcomes and marginalization in workplaces compared to their non-disabled counterparts. Statistics Canada (2012) data indicates that persons with mild ${ }^{5}$ disabilitieswhich is typical level of severity of university GLD-have slightly higher unemployment rates (8.3 percent) than non-disabled Canadians (6.8 percent). Disability scholarship (Macan 2009; Schur, Kruse and Black 2005) links barriers in the recruitment process to broader stereotypes about disability, lack of disability awareness and inadequate resources to promote job-seekers employment in both private and public sector industries.

Once employed, persons with disabilities continue to experience unfavorable outcomes compared to their non-disabled co-workers. For instance, Kaye (2009) found that even when controlling for educational attainment, persons with disabilities in mainstream workplaces are "disproportionately relegated to entrylevel occupations that do not emphasize the better-remunerated job skills... [which] results in lower wages and less job security and stability" (115). Hall (1999) and others (Barnes and Mercer 2005; Wilton 2004) point out that the marginalization of persons with disabilities in work reflects broader constructions of disability that prescribe ableist norms of how employees can work, such as the expected response times for emails, or conducting office work in a 'normal' office chair.

There are fewer examples of scholarship that considers the implications of these embedded norms for persons with learning disabilities. Baron and colleagues (1998) emphasized that the nature of 'speedy' work can present challenges for persons with learning disabilities: 
[...] where tasks change rapidly and start-up costs are to be minimized in the increasing frantic search for profitable investment. People with LD tend to learn slowly; slow learners are expensive. People with learning difficulties tend to produce slowly; slow producers are less profitable (102).

In this context, the nature of work links the cognitive capacity of the worker to the profitability of the organization. Combining this capacity with the pressure for speedy work can present challenges for workers with LD who cannot perform in such ways. Studies (e.g., Butcher and Wilton 2008; Hall and McGarrol 2012) that take interest in the experiences of persons with LD have typically engaged with those living with severe cognitive impairments. These studies are often concerned with labour market exclusion. At the same time, there is relatively little work on the experiences of persons with cognitive impairment who have greater social capital in the labour market. Thus, our understanding of the 'hidden geographies' (see Hall 1999) of the 'more employable' persons with LD is lacking. This study seeks to explore the experiences of this sub-group.

\section{SMART WORKER STANDARD}

In this study, the focus is on GLD's efforts to transition into employment within the knowledge economy. In particular, the study is concerned with how GLD negotiate workplace performance expectations that reflect a 'smart worker' standard. This study engages with Billett's (2000) conception of the smart workforce with the intent of pointing out the disabling nature of workplace expectations placed on entry-level employees. He defines the smart workforce as encompassing:

[...] the dimensions of work practice [that] go beyond identifying 'technical skills', and work organization to include the ways individuals need to engage in work practice that variously may need to be flexible, adaptable or, conversely, highly consistent given the particular requirement (123).

This study defines 'smart workforce' as work performance expectations that go beyond technical skills or domain specific knowledge but also expectations that are also sensitive to the socio-cultural systems of the work activities. These expectations 'can be considered as the external embodiment of the workplace' (Billett 2000: 138). For example, what is considered to be a 'competent' performance of an account manager might involve a distinct memory for clients' personal information, innovative marketing approaches to new clientele or a longstanding client base. The understanding of which traits are valorized and how to achieve this standard requires experience in work.

This study provides a conceptual critique of the smart workforce from a disability perspective. Using the Baron's analysis of speedy work (as discussed 
above), this study examines how (often implicit) workplace expectations of flexibility, speed and adaptability can be disabling for GLD. New employees are expected to quickly learn, for example, the workplace's protocol for drafting a meeting briefing such as procedural steps, language and formatting. Those employees whom might struggle with, for example, language conventions can be subject to the pressure and politics of concealing their writing process.

The construction of the smart worker is particularly important for entry-level, first-time employment candidates with LD who are competing in the labour market against other candidates with similar credentials. Competition places candidates in a position of vulnerability to display 'appropriate performances' (Holt 2007). There is little known about the ways in which persons with LD persuade their minds to behave in expected ways, or to approximate a smart worker standard. Moreover, there is little known about how GLD negotiate the LD label. As GLD attempt to negotiate the smart worker standard, questions of passing ${ }^{6}$ and disclosure are likely to be central to their experience. For individuals who live with more invisible disabilities the issue of (non) disclosure is pertinent.

\section{METHODOLOGY}

\section{SETTING}

The setting of this study is a large university in Southern Ontario. The university's disability centre provides service to roughly 1,200 students on the main campus in a given year. In addition to academic services, the centre offers a year-long mentorship program specific to students with LD. This program offers an opportunity for students to be connected with a mentor who is currently employed in the student's industry of interest.

\section{PARTICIPANTS}

There were 20 participants in this study: eight mentee and 12 mentor participants. The mentees are comprised of seven undergraduate students and one graduate student from the university. The mentee and mentors of this program are well suited for this analysis since most have personal experience with issues related to transition for GLD. Their insights offer a valuable set of perspectives because they start the transition process as some are approaching transition, while others have successfully entered the labour market.

All mentees are registered with the Disabilities Services on campus and sought to participate in the mentorship program to help facilitate their transition to work. The age of the mentees ranged from 18 to 33 years of age. All mentees were Canadian citizens, single with no children. They all registered for the 
mentorship program because they were interested in issues surrounding transition into work for GLD.

The 12 mentors who were interviewed were at various career stages. With the exception of one retiree, the mentors identified as currently holding full-time employment positions in what would be considered knowledge work. Two of these individuals were self-employed. The age of the mentors varied between 24 to 63 years of age. All mentors expressed an interest in the issue of transitioning into knowledge work for GLD and all but two disclosed privately to having a LD. All mentors, except for one, had completed a university degree.

\section{INTERVIEW METHOD}

In this research, two forms of interview methods were used: traditional researcher-participants method and peer-interviews among participants. A traditional interview method is employed with the mentors of the LD mentorship program; whereas the peer-interview method was used with the mentees. The peer interviews were tape recorded and transcribed. A more detailed description about the peer interviews can be found elsewhere. The reason for the difference in methods between these two groups is due to the fact that the mentees engaged in research activities as part of a larger participatory action research (PAR) project. Due to scheduling conflicts with the mentorship program, none of the mentors were able to participate in this PAR project in the same way as the mentees. Thus, mentors were offered the opportunity to participate in the research project through traditional one-on-one interviews with the author. Interviewing the mentors outside of the PAR project served to meet the study goal to integrate the experiences of persons with LD who are currently in the labour market. The use of both mentee and mentor data allows for a triangulation of experiences in transition and over the course of one's career path.

\section{INTERVIEW PROCEDURES}

Initial contact with potential participants took place during the first mentorship meeting in the fall of 2011. Present at this meeting were both mentors and mentees. The author was given time to present a short introduction of herself and her project, and to offer an invitation to participate in the study. The nature of the presentation invited potential respondents-both mentors and mentees-to participate in the study. The interviews were arranged at a convenient location for each respondent, and with permission, these interviews were audio recorded. 


\section{DATA COLLECTION}

Respondent interviews were semi-structured and used open-ended questions. Interviews involved a process where it is not merely about "collecting data but also a site where data is co-constructed, where identities are forged through the telling of stories and meaning making begins" (Doucet and Mauthner 2008: 335). The interview guide questions addressed themes of disclosure, accommodation request, disability perceptions at work and in school, disability identity and experience of LD at work and in transition. The questions derived thematically from disability and geographical literature.

\section{ANALYSIS}

Audiotapes from the mentor interviews were transcribed in full by the author. To protect the identity of respondents, all names are pseudonyms. In an effort to produce a 'nuanced' account of social exclusion (and inclusion) (see also Hall 2004), the transcripts were coded thematically and analyzed according to sequential stages of the recruitment process. Grounded theory was used to create thematic codes and categorizes. These categorizes served as basis for the creation of the 'catch-22' theory as it relates existing literature in disability studies, human geography and human resource management (Boyatzis 1998).

\section{RESULTS}

This section is organized according to three key employment stages in the transition into knowledge work: the interview process, employment testing and the probationary period. This section examines how, at each stage, aspects of the smart worker standard create pressure to conceal one's disability in order to avoid being flagged as a problem worker. This produces a dilemma for GLD as to whether, how and when to disclose one's disability.

\section{THE INTERVIEW PROCESS}

With the ever-growing number of applicants entering university, undergraduate degrees represent merely the 'first among many ticks in the box' (Brown and Hecketh 2004). Graduates with and without disabilities enter the labour market with similar resumes: little work experience and a university degree. In Canada, GLD have two hiring pathways: through mainstream or diversity-hiring streams. The latter case has emerged in Canada, in part from Canadian legislative frameworks such as the Employment Equity Act ${ }^{7}$ (EE) and in part from employer-driven initiatives to offer equal opportunity to all candidates in recruitment. 
In mainstream recruitment, the visibility of a disability is central to an interviewee's capacity to perform as non-disabled. For GLD, the possibility to pass as non-disabled is typically an option. However, non-disclosure results in forgoing accommodation requests, whereas disclosure of one's disability might result in fear of prejudice. Disclosure during the interview stage was rare (two mentors), typically because respondents felt they 'didn't need accommodation' or they felt that their disability would have had a negative impact upon their interviewer's perception.

This hesitation to disclose one's LD has been well documented in the literature (Kakela and Witte 2000; Madaus 2008a; Price et al. 2003; Adelman and Vogel 2000). Baderi, a recent graduate and past mentee of the mentorship program, articulates her rationale for not disclosing: "I don't know why [the interviewer] would hire me as opposed to somebody else who doesn't have a disability that have wouldn't have any challenges". She worries that her disability will be perceived as a burden to a potential employer. At the same time, she explains how she would profit from accommodations during the interview:

And every time I go to an interview I always feel like it would maybe be to my benefit to say 'listen, I might need some notes because I find it really hard to remember all the lingo, as well as answer the questions'. As well as remembering, because what they do is they ask you like a four-part question in one question and don't, allow you to write anything down because they say that it doesn't, it's not fair for the other candidates if I bring in notes... So I don't know, I haven't yet disclosed to be honest, but I think it might be to my advantage. Although I'm scared that it would stop me from getting a job.

Many respondents in this study expressed concern that interviewers would interpret their disability as an indication that they would not be able to meet the employers' expectations, as a tactical excuse for lack of intelligence or, as in Baderi's case, an attempt to gain an unfair advantage during the interview.

An alternative to the mainstream recruitment process is the diversity stream that is arguably more accustomed to accommodation requests by applicants. The diversity stream of recruitment seeks to: a) attract designated groups as defined by the EE Act; b) recruit from populations that may have not otherwise applied; and, c) foster an inclusive recruitment process that is sensitive to the various needs of designated groups (see Equity and Diversity Directorate 2011). Seeking employment through the diversity stream entails declaring an affiliation to at least one of the designated groups. In many cases, disability recruitment occurs at events for 'disabled' candidates. Neil, a mentor in his early thirties, and a past participant in the mentorship program, had recently entered the workforce after 
completing his bachelor's degree in business. He reflected upon his experience with retail bank diversity hiring counselors:

[For work in] Private equity you have to be like the cream of crop, you have to be the best. So as soon as you, like, you meet one of these diversity counsellors and you say: 'well I want to do private equity'. They look at you as if, 'yeah, I don't think I can get you in there'. Not because they don't want to but they know if they go to the managing director of that department and say: 'look I have someone with a disability'; [the managing director] is just going to say 'no' right away: 'Well we only want the best and the smartest' right? Even though you may be the best and the smartest, they won't accept you.

This experience may be illustrative of the existence of a glass ceiling in the EE stream. In spite of the bank's EE policy, some opportunities were effectively unavailable and even discouraged through the diversity pathway. Situations such as Neil's may be linked to some of the criticisms offered by scholars such as Verbeek (2011) and others (Levinson and Parritt 2005; Hyde 1998; Ng and Burke 2005; Cunningham et al. 2004; Stevens 2002), who highlight problems with the well-intended purposes of EE policies and their practical outcomes. For instance, Gillies' (2012) research on the transition to work for university graduates with disabilities found that legislative and policy initiatives "offer limited assistance in decreasing the negative stereotypes that exist regarding persons with disabilities" (2). Baderi's experience involved adjusting her demeanor-not taking notes - in order to pass as non-disabled. In Neil's case, he attempted to resist the negative stereotypes about disability by using EE programs. In both instances, the smart worker standard is evident in the hiring process insofar as the norms demarcate how employees should perform in order to be considered for knowledge work opportunities.

Experiences in both these hiring schemes point to the persistence of the stereotypes of incompetency and lack of intelligence. These stereotypes function in a circular relationship with individual-level challenges such as poor selfesteem and self-confidence. Several studies have noted that students with LD are more likely to face negative self-perceptions (Lackaye and Margalit 2006), peer rejection and loneliness (Margalit 1994). Dipeolu and colleagues (2002) have reported that students with LD's self-perception of worthlessness can serve to undermine their career potential.

\section{EMPLOYMENT TESTING}

Employment testing has become an influential way of measuring the employability of job applicants in a seemingly objective and efficient manner. General Cognitive Ability (GCA) testing is widely employed by organizations for 
hiring purposes as a predictor of future work performance and training success (for a discussion see, Hunter et al. 2012). These GCA tests seek to assess the "general mental faculty that includes the ability to reason, plan, solve problems, think abstractly, comprehend complex ideas, learn rapidly, and apply one's life experiences to new situations" (Denis and Gilbert 2012: 541). Such tests are arguably a manifestation of the smart worker standard because they seek to measure the cognitive performance of employment candidates. These testing situations pose considerable obstacles for candidates who require test accommodations.

In this pre-employment stage, study respondents reported that they were unlikely to disclose their disability or request accommodations. Of the five mentors who were required to complete a GCA test, only one mentor requested accommodations $^{8}$. It is interesting to note that Scott, the mentor who did request accommodations, was not provided with his accommodation to write on a computer. He describes his experience as 'ridiculous', inasmuch as the employer denied his request for the use of a computer because spell check was seen as an 'unfair advantage' and further claimed that 'it's too much work to take it off'. The remaining four mentors reported that they did not request accommodations and, consequently, they all reported that they did not perform to their potential. The GCA test process presented another 'catch-22' situation. On the one hand, respondents expressed concern that the GCA test performance would show their LD. On the other hand, requesting the appropriate accommodations would require the disclosure of one's disability. In both circumstances, they would be flagged as disabled or as a poor performer (see also, Hazer and Bedell 2000).

Some of the mentors, such as John, refused the GCA testing altogether. John was offered a position that required him to take an aptitude test, which he unequivocally refused:

I got a phone call from a head-hunter saying, 'Oh, there's this consulting company that, you know, they're interested in you'... It was a telephone interview, so I did this telephone interview and they said 'Everything's great and wonderful, now we want you to do those aptitude tests', like intelligence test, an IQ test thing. And at first I said: 'No'; I said 'No, I'm not going to do it, it's not going to happen'. You know what, they go: 'Well, you have to do it, everyone in our company does it'. 'That's great but I'm not doing it', you know. And they go: 'Well why not?' And I said: 'Because you're hiring me for, you know, for my skills that I have, you know, you see that I can do this', you know. And I refuse to do it because I knew what would happen. They'd see my writing, they'd see everything else, and say: 'You're out'.

As shown in John's case, GCA testing presents a dilemma for GLD. Although in the regular course of employment John found ways to deal with his writing difficulties, he refused to write the GCA test because he feared being flagged as 
disabled within this organization. Yet, his failure to complete the test undoubtedly prevented him from obtaining the position.

A specific issue identified by respondents with GCA testing was the time limit format/requirement, also known as the speed mode (for a discussion see Schlemer 2007). This is, perhaps, not surprising since extra time is, for students with LD, the most commonly administered accommodation for test taking (Lindstrom and Hartwig 2007). The literature suggests that, under speed mode conditions, performance on GCA is negatively affected by test anxiety (see Ackerman and Heggestad 1997; Wicherts, Dolan and Hessen 2005). In the same way, Sena, Lowe and Lee's (2007) study of students with LD found that these students had greater cognitive obstruction/ inattention and worried more about testing compared to their non-LD peers. Together, the study results and this literature suggest that GLD might be at a distinct disadvantage on GCA testing due to the absence of appropriate accommodations, further compounded by the negative effects of test anxiety under speed mode conditions (recommendations to address this issue are discussed in the conclusion).

\section{THE PROBATIONARY STAGE}

For any employee, a probationary period is critical to demonstrate work competencies to their new employer. In the traditional sense, the probationary period refers to the period of time in which the employer evaluates the personjob fit of a particular candidate (both with and without a disability), and the candidate can become accustomed to the work process and culture. However, the analysis in this study reveals that there is also a probationary period from the perspective of the employees with LDs. This period was conceived of by respondents as the time it takes to prove their work competency, or as Mark puts it: "once I prove to my employer... that, yes, I am normal".

For respondents, the length of the probationary period ranged between a few weeks to two years. This duration was influenced by a number of factors including their perceived employment security and the sense of having cultivated a positive relationship with supervisors and coworkers. During this probationary period, respondents used a diverse array of coping strategies in an effort to prove themselves as smart workers.

During the probationary period, some respondents used coping strategies to navigate challenging situations. Lorna, a mentor, for example, describes how she would read her written work word-by-word in reverse to ensure correct spelling. Lorna believes that persons with LD should not be expected to perform in the same ways as non-LD individuals. She argues: 
[...] you have to find a way to make it easy for you, it shouldn't have to make it hard, if you can find the right way to do it, but that's different from other people, and that's the hardest thing for them to let go if they want to do the regular way.

In order words, for Lorna, it is essential that GLD develop individualized strategies to negotiate their particular workplace challenges. The most cited strategies among respondents include: arriving early and/or staying later at work, time management strategies (e.g., timetabling), and checking for understanding with one's supervisor. These strategies coincide with findings from other studies (Holmes and Silverstein 2011; Madaus 2008).

During the probationary process, some respondents developed rather creative strategies to negotiate workspaces in order to be perceived as 'normal' as possible. For example, Ashley, a mentee, had been employed at a cultural arts center. She describes how she concealed her disability for the first few months while she gained the credibility with her employer. During this time, she would place stickers on co-workers' desks that corresponded to a floor plan she had drafted. This strategy assisted her in recalling names, titles and other important details of fellow co-workers:

I don't normally like to tell employers [that I have a LD] at an interview process. I usually like telling them afterward because that can give them the notion that this person can't do the task or not do the job. And I don't want to mislead them, in any way. I like to prove to my employers, the first two weeks or three weeks, that I'm hired that: 'yes, I am normal, I can', 'OK, maybe she's a little strange, that she puts sticky notes everywhere'. But I'd rather they think that I'm a bit strange, than that I have this LD, that hinders me from doing the work.

Although Ashley states she does not want to mislead her employer, she sees the two-week period as a buffer where she is able to prove her capacity to be a productive worker before disclosing her disability. Ashley appears to employ what Gerber et al. (1992) call learned creativity inasmuch as she considers how she can leverage her strengths of problem solving in order to compensate for her weakness in memory. Moreover, for this short period, she opts to be perceived as 'strange' in an effort to negate the prejudice she feels might be associated with her LD. In other studies (see Brohan et al. 2012; Lee et al. 2006), concealing one's disability, as in Ashley's case, involves choosing between disclosure of one's potentially stigmatized LD identity or risk being perceived as anotherpotentially more socially damaging-identity such as lazy or competent. This concealment comes at an emotional cost. Brohan and colleagues (2012) note: "the experience of constructing a 'cover story' to explain unusual behaviour is described as a source of shame and an energy draining activity" (8). 


\section{DISCUSSION}

The purpose of this article was to explore the experiences of GLD negotiating the transition into knowledge work. Using interview data from GLD in university and individuals with LD in the workforce, key employment stages were explored. The findings point toward a 'catch-22' situation where respondents are actively engaged in the negotiation of the smart worker standard. Negotiating transition into knowledge work for GLD involves using diverse passing and resisting strategies.

The data analysis demonstrates that the smart worker standard is a central theme in the experiences of transition to work for GLD. The interview process, for example, serves to disadvantage those who do not perform in ableist ways. For instance, candidates are expected to perform the interview without access to accommodation tools (such as note-taking) in order to ensure the perception of fairness. Thus, candidates are caught in the 'catch-22' of requiring accommodation during this process but fearful of the associated stereotypes of laziness, stupidity and the like that could result from such a request. Yet, without accommodations the interview process is anything but fair for them. Moreover, the analysis suggests that hiring pathways in EE programs can be problematic for candidates with disabilities who wish to be considered for more cognitively demanding employment opportunities. GLD must negotiate this hiring process by weighing the potential stigma associated with disclosure of disability against their accommodation needs As a whole, most GLD do not disclose their disability at this stage of the employment process which contributes to the 'hidden geographies' of the more employable person with LD.

At the GCA testing, there is a significant deterrent for GLD transitioning into employment. Testing can be interpreted critically as systematic discrimination against applicants with LD for several reasons. First, the cognitive test might (or at least can be perceived to have the potential to) expose an individual's cognitive (dis)abilities. This is clearly a concern to individuals with LD who may not perform at the same speed, quality and/or fashion as a (non-disabled) norm. Respondents strongly felt that if they took such a test, their impairment would likely surface and disqualify them from obtaining the position. For most respondents, the option to request accommodation was simply out of the question. Any request for accommodation would risk 'outing' their disability which would conflict what Baron and colleagues (1998) noted as the norm for 'speedy work'. During this pre-employment stage, disclosure was largely avoided. A key question emerging from the respondents' concerns over GCA testing is: how can employers administer testing in a non-discriminatory fashion wherein individuals with LD may not need to disclose? An obvious solution would be to provide the most commonly used accommodation, additional time. This accommodation might alleviate performance discrepancies among some 
candidates and offer an equal opportunity for GLD candidates to demonstrate their GCA potential. This recommendation is supported by the literature that has found that extended test times are more likely to predict actual job performance, for employees with and without disabilities, than restricted timed tests (Denis and Gilbert 2011).

The experiences of the respondents suggest that GLD negotiate workspaces by attempting to perform in expected ways during the probationary period. One finding of this study concerns the extent to which GLD's own sense of just how long they are 'on probation' in a new job extends, sometimes significantly, beyond the formal period established by an employer. For GLD, this probationary period is defined by the time it takes for them to prove themselves as an employee. In many ways, the probationary period is a time in which they are actively engaged in negotiating the complex politics of passing/resisting. The initial probationary period involves the use of a number of coping and creative learning strategies. Most respondents noted that disclosure was important to them and did so after the perceived probationary period. This is an important finding considering the fact that the literature such as Holmes and Silverstein (2011) suggest that most GLD will not disclosure their impairment in spite of the negative impact on performance. The findings of this study suggest that disclosure typically does take place. However, it occurs at a point in which the employees feel secure in their employment relationship. It is arguable that an individual's ability to approximate the smart worker standard during this timeframe will be determined by their resourcefulness and their ability to draw upon these various strategies. However, these strategies do not occur in a vacuum. They are the product of self-awareness and self-advocacy processes. The literature has suggested that processes can be fostered through postsecondary programs such as the Ontario Learning Opportunity Task Force program and other mentorship programs. These programs involve "intensive learning skills, education, and self-advocacy intervention" (Harrison et al. 2012, 57).

This article has examined how workplaces can be disabling for individuals with cognitive differences, specifically LD. Taking particular interest in initial employment process, it is examined how GLD can find themselves in a 'catch-22' position between as a non-disabled employee passing and resisting smart worker standards. The analysis of this article demonstrates how employers and human resource managers can apply a geographic approach to the workplace policies and practices in order to critically appraise how the workplace such as the interview process and employment testing can be (dis)abling. 


\section{CONCLUSION}

Increasing numbers of GLD are transitioning into knowledge work by negotiating smart worker standards. These standards are reflected in the expectation that candidates perform according to the organizational/industry ableist norms. The realities of GLD experiences are important to disability theory in understanding how these critical transitional stages can present unique structural and individual barriers and opportunities. This article demonstrates how GLD are caught in a 'catch-22' of fearing prejudice based disclosure of one's LD and non-disclosure which can lead to stigma for work performance. Mindfully, they engage in the politics of passing/resisting as a non-disabled candidate. Many of the respondents eventually disclosed their LD at work, once they felt secure to do so. These findings are timely as there is a growing interest in-and need to-recruit university graduates to fulfill knowledge work demands. Future research should detail the implications of the changing temporal demands of work for persons with LD; the various coping strategies and accommodation resources employed by GLD. In this article, it is considered how persons with LD negotiate the social-cultural norms of the workplace. Conceptually, this allows for reframing disability as a product of the interaction between the individual, workplace or potential workplace, and not inherently as the result of intellectual inadequacies. These considerations are imperative to advance workplace accommodations to foster diverse and productive workplaces. As Lorna put it: "a person that has developed the right accommodations are far often far more likely more productive than other people in the same job because...they are maximizing their strengths".

\section{NOTES}

1 Learning disability makes reference to "a variety of disorders that affect the acquisition, retention, understanding, organization or use of verbal and/or nonverbal information" (Learning Disability of Ontario, 2001, p.1)

2 'Catch-22' makes refers to a situation where an individual cannot escape from a paradoxical problem due to contradictory constraints.

3 There is a 7 percent difference in employment rate and comparable earnings $(\$ 40,547$ for non-disabled bachelor degree graduates and $\$ 40,307$ for the GLD counterparts) (HRSDC, 2011).

4 Originally proposed by Goffman's work on passing, this term refers to "the processes of keeping a stigmatized identity successfully concealed... to be treated the same as anyone else in the workplace" (Brohan et al. 2012, p. 5).

5 There is vast diversity of persons and impairments within the disability community. The reference to mild disabilities is the terminology used by Statistics Canada, which is measured by the intensity and frequency of activity limitation. This is an important 
distinction from other disability severity types, such as severe, since activity limitations influence an individual's employment prospects.

6 Devlin and Pothier (2006) talk about 'the possibility (and politics) of passing' - a concept that can be realized by the invisible nature of certain disabilities, such as LD (15). Passing may depend upon strategies, such as staying late at work, in order to perform in non-disabled ways.

7 The Employment Equity Act seeks to "achieve equality in the workplace by removing barriers to employment for the designed groups" including persons with disabilities. The Act applies to parts of the federal public service, some Crown corporations and a small number of federally regulated private sector employers (Government of Canada, 2011).

8 It is important to note that a limitation of this study is that none of the respondents had positive experiences in obtaining accommodations for employment testing.

\section{REFERENCES}

Ackerman, P. L., and Heggestad, E. D. 1997. “Intelligence, personality, and interests: Evidence for overlapping traits." Psychological Bulletin 121: 219-254.

Adelman, P. B., and Vogel, S. A. 1993. "Issues in the employment of adults with learning disabilities." Learning Disabilities Quarterly 16(3): 219-232.

Artiles, A. J., and Kozelski, E. B. 2007. "Beyond convictions: Interrogating culture, history, and power in inclusive education." Language Arts 884(4): 357345.

Baron, S., Riddell, S., and Wilkinson, H. 1998. "The best burgers? The person with learning difficulties as workers." Pp. 94-109 in The Disability Reader: Social Science Perspectives, edited by T. Shakespeare. London: Cassell.

Barrette, J., Garcia, L. J., and Laroche, C. 2009. "New Considerations for Employers Regarding Workplace Integration: The Impact of Communication Disorder." International Journal of Disability, Community \& Rehabilitation 1(1): 113. Retrieved August 92014 http://www.ijdcr.ca/VOL01_01_CAN/articles/barrette.shtml

Beruvides, M. G., and Koelling, C.P. 2001. "An investigation of the work characteristic composition in blue-collar, white-collar, and knowledge work." International Journal of Human Resources Development and Management 1(2):283303.

Billett, S. 2000. "Performance at work: Identifying smart work practice." Pp. 123150 in Training for a Smart Workforce edited by R. Gerber and C. Lankshear. Routledge: London.

Blackorby, J., and Wagner, M. M. 1996. "National post school outcomes of youth with disabilities: Findings from the National Longitudinal Transition Study." Exceptional Children 62: 399-414. 
Boyatzis, R. E. 1998. Transforming qualitative information: Thematic analysis and code development. Sage: California.

Brooks R. Vostal, Hughes, C. A., Ruhl, K. L., Benedek-Wood, E., and Dexter, D. D. 2008. "A Content Analysis of Learning Disabilities Research and Practice: 1991-2007." Learning Disability Research and Practice 23(4): 184-193.

Brohan, E., Henderson, C., Wheat, K., Malcolm, E., Clement, S. Barley, E. A., Slade, M., and Thornhicroft, G. 2012. "Systematic review of beliefs, behaviours and influencing factors associated with disclosure of a mental health problem in the workplace." BMC Psychiatry 12(11): 1-14.

Brown, P., and Hesketh, A. 2004. Mismanagement of talent: Employability and Jobs in the knowledge economy. Oxford: Oxford University Press.

Butcher, S., and Wilton, R. 2008. "Stuck in transition? Exploring the spaces of employment training for youth with intellectual disability." Geoforum 39: 1079-92.

Cunningham I., James, P., and Dibben, P. 2004. "Bridging the gap between rhetoric and reality: Line managers and the protection of job security for ill workers in the modern workplace." British Journal of Management 15: 274-90.

Denis, P. L., and Gilbert, F. 2012. "The effect of time constraints and personality facets on general cognitive ability (GCA) assessment." Personality and Individual Differences 52(4): 541-545.

Devlin, R. F., and Pothier, D. 2006. "Introduction: Toward a critical theory of discitizenship." Pp. 1-22 in Critical disability theory: Essay in philosophy, politics, policy and law edited by R. F. Devlin and D. Pothier. University British Columbia Press: Vancouver.

Dipeolu, A., Reardon, R., Sampson, J., and Burkhead, J. 2002. “The Relationship between Dysfunctional Career Thoughts and Adjustment to Disability in College Students with Learning Disabilities." Journal of Career Assessment 10(4), 413-427.

Doucet, A., and Mauthner, N. 2008. "Qualitative interview and feminist research." Pp. 328-343 in The SAGE Handbook of Social Research Methods edited by P. Alasuutari, L. Bickman, and J. Brannen. London: SAGE Publications.

Equity and Diversity Directorate. 2011. Recruitment of persons with disabilities: A literature review (Cat. No. SC3-156/2011E-PDF). Ottawa: Public Service Commission of Canada. Retrieved August 92014 http://www.psc-cfp.gc.ca/plcy-pltq/eead-eeed/rprt/pwd-ph/index-eng.htm

Gerber, P. J., Ginsberg, R., and Reiff, H. B. 1992. "Identifying alterable patterns in employment success for highly successful adults with learning disabilities." Journal of Learning Disabilities 25(8), 475-487.

Gillies, J. 2012. "University graduates with a disability: The transition to the workforce." Disability Quarterly 32(3). Retrieved August 92014 
http://dsq-sds.org/article/view/3281/3115

Goffman, E. 1963. Stigma: Notes on the Management of Spoiled Identity. Harmondsworth, Middlesex: Penguin Books.

Greenbaum, B., Graham, S., and Scales, W. 1996. "Adults with learning disabilities: Occupational and social status after college." Journal of learning disabilities 29(2): 167-173.

Hall, E. 1999. “Workspaces: Refiguring the disability-employment debate." Pp. 135-150 in Geographies of illness, impairment and disability edited by R. Butler and H. Parr. Routledge: New York, NY.

Hall, E., and McGarrol, S. 2012. "Bridging the gap between employment and social care for people with learning disabilities: Local Area Co-ordination and in-between space of social inclusion." Geoforum 43(6): 1276-86.

Hansen, N., and Philo, C. 2007. "The normality of doing things differently: Bodies, space and disability geography." Tijdschrift voor Economische en Sociale Geografie 98(4): 493-506.

Harrison, A. G., Areepattamannil, S., and Freeman, J. 2012. "Effects of the Learning Opportunity Task Force (LOTF) programs on postsecondary students with learning disabilities." Exceptionality Education International 22(1): 55-69.

Harrison, A. G., and Wolforth, J. 2007. Results from a national survey of disability service providers in the Canadian post-secondary system. Unpublished manuscript.

Hazer, J. T., and Bedell, K. V. 2000. "Effects of seeking accommodation and disability on preemployment evaluations." Journal of applied social psychology, 30(6): 1201-1223.

Hazel, D. 2008. "Deconstructing barriers: Perceptions of students labeled with learning disabilities in higher education." Journal of Learning Disabilities 41(6): 483-497.

Holmes, A., and Silverstein, R. 2011. "Employment Experience of Ontario's Postsecondary Graduates with Learning Disabilities." Higher Education Quality Council of Ontario, 1-58.

Holt, L. 2007. "Children's socio-spatial (re)production of disability in primary school playgrounds." Environment and Planning D: Society and Space 25: 783802.

Hunter, S. T., Cushenbery, L., and Friedrich, T. 2012. "Hiring an innovative workforce: A necessary yet uniquely challenging endeavor." Human Resource Management Review 22(4): 303-322.

Human Resources and Skills Development Canada (HRSDC). 2009. Advancing the inclusion of people with disabilities. Government of Canada: Cat. No.: HS611/2009E-PDF 
-------. 2011. Disability Facts about the Labour Force. Retrieved August 92014 http://www.hrsdc.gc.ca/eng/disability_issues/reports/disability_profile/2011/fac t_sheet/labour_force.shtml

Hyde, M. 1998. "Sheltered and supported employment in the 1990s: The experiences of disabled workers in the UK." Disability and Society (13)2: 199215.

Jin, D. J., and Stough, R. R. 1998. "Learning and learning capacity in the Fordist and post-Fordist age: An integrative framework." Environment and Planning 30: 1255-1278.

Kakela, M., and Witte, R. 2000. "Self-disclosure of college graduates with learning disabilities." Learning Disabilities: A Multidisciplinary Journal 10: 2531.

Kaye, H. 2009. "Stuck at the Bottom Rung: Occupational Characteristics of Workers with Disabilities." Journal of Occupational Rehabilitation 19(2): 115-128.

Lackaye, T. D., and Margalit, M. 2006. "Comparison of achievement, effort and self-perception among students with learning disabilities." Journal of Learning Disabilities 39(5): 432-446.

Learning Disability Association of Ontario. 2001. Learning Disabilities: A New Definition. Toronto: Learning Disability Association of Ontario. Retrieved August 92014

http://www.ldao.ca/documents/Definition_and_Suporting percent20Document_2001.pdf

Levinson F., and Parritt, S. 2005. "Against stereotypes: Experiences of disabled psychologists." Pp. 111-122 in Disability and psychology edited by D. Goodley, and R. Lawthom. Basingstoke, UK: Palgrave Macmillan.

Li, C., Gervais, G., and Duval, A. 2006. "The dynamics of over-qualification: Canada's underemployed university graduates." Statistics Canada. Retrieved August 92014 http://www.statcan.gc.ca/daily-quotidien/060406/dq060406c-eng.htm

Lindstrom, J. H., and Gregg, N. 2007. "The role of extended time on the SAT for students with learning disabilities and/or attention-deficit/hyperactivity disorder." Learning Disability Research and Practice 22(2): 85-95.

Longhust, R. 2010. “The disabling affects of fat: The emotional and material geographies of some women who live in Hamilton, New Zealand." Pp. 199216 in Towards Enabling Geographies: 'Disabled' Bodies and Minds in Society and Space edited by V. Chouniard, E. C. Hall, and R. Wilton. Farnham, England: Ashgate Publishing Limited.

Macan, T. 2009. "The employment interview: A review of current studies and directions for future research." Human Resource Management Review 19(3): 203-218. 
Madaus, J. W., Gerber, P. J., and Price, L. A. 2008. "Adults with learning disabilities in the workforce: Lessons for secondary transition programs." Learning Disabilities Research and Practice 23(2): 148-153.

Madaus, J. W., Zhao, J., and Ruban, L. 2008. "Employment satisfaction of university graduates with learning disabilities." Remedial and Special Education 29(6): 323-332.

Margalit, M. 2004. "Second-generation research on resilience: Social-emotional aspects of children with learning disabilities." Learning Disabilities Research and Practice 19: 45-48.

May, A., and Stone, C. 2010. "Stereotypes of Individuals With Learning Disabilities: Views of College Students With and Without Learning Disabilities." Journal of learning disabilities 43(6): 483-499.

Meredith, M. A. 2005. "Transition and beyond: A multi-case study on employment stability as a post-school outcome for six young men with learning disabilities." Dissertation, 1-24. Retrieved August 92014 http://search.proquest.com.myaccess.library.utoronto.ca/docview/30544197 2/9F33F93FFC424778PQ/1?accountid=14771

$\mathrm{Ng}$, E., and Burke, R. 2005. "Person-organization fit and the war for talent: does diversity management make a difference?" The International Journal of Human Resource Management 16(7): 1195-1210.

Organization for Economic and Cooperative Development (OECD). 2003. "Disability in Higher Education." OECD Publishing. Retrieved August 92014 http://www.oecd-ilibrary.org/education/disability-in-highereducation_9789264105072-en

Price, L., Gerber, P. J., and Mulligan, R. 2003. "The American with disabilities act and adults with learning disabilities as employees: The realities of the workplace." Remedial and Special Education 24(6): 350-358.

Ren, L. R., Paetzold, R. L., and Colella, A. 2008. "A meta-analysis of experimental studies on the effects of disability on human resource judgments." Human Resource Managment Review 18: 191-203.

Schlemer, L. T. 2007. "Test speediness and cognitive styles: A study using CAT version of the SAT." Dissertation Abstracts International 68(10): UMI No. AAI3283717).

Schur, L., Kruse, D., and Blanck, P. 2005. “Corporate culture and the employment of persons with disabilities." Behavioral Science Law 23(1): 3-20.

Sena, J. W., Lowe, P., and Lee, S. 2007. "Significant predictors of test anxiety among students with and without learning disabilities." Journal of Learning Disabilities 40(4): 360-376.

Statistics Canada. (2012). Labour force survey estimates (LFS), by educational attainment, sex and age group. Retrieved from Statistics 
Canada website:

http:/ / www5.statcan.gc.ca/cansim/pickchoisir?lang=eng\&p2=33\&id=2 $\underline{820004}$.

Stevens, G.R. 2002. "Employers' perceptions and practice in the employability of disabled people: A survey of companies in Southeast UK." Disability and Society 17(7): 779-96.

Verbeek, S. 2011. "Employment equity policy frames in the literature: 'good practice' versus 'bad idea'." International Journal of Human Resource Management 22(9): 1942-1962.

Wicherts, J. M., Dolan, C. V., and Hessen, D. J. 2005. "Stereotype threat and group differences in test performance: A question of measurement invariance." Journal of Personality and Social Psychology 89: 696-716.

Wilson-Kovacs, D., Ryan, M. K., Haslam, A. S., and Rabinovich, A. 2008. "'Just because you can get a wheelchair in the building doesn't necessarily mean that you can still participate': Barriers to the career advancement of disabled professionals." Disability and Society 23(7): 705-717.

Wilton, R. 2004. "From flexibility to accommodation? Disabled people and the reinvention of paid work." Transactions of Institute of British Geographers 29: 420-32.

Yates, W. N. 2009. “Enabled Voices: An Interpretive study of the 'lived experiences' of young adults with disabilities during their transition to the workplace." Dissertation Abstracts International, 1-24. 